\title{
Im Sommer spritzt man nicht
}

\section{Den Beitrag „Ungerechtfertigte Abbrüche der Bienengift-Hypo- sensibilisierung" von F. Ruëff et al. (Allergo Journal 2002; 11: 104-8) ergänzt der folgende Leserbrief mit einem kleinen Fallbericht zum Schmunzeln.}

$M$ it großem Interesse haben wir drei in Gemeinschaftspraxis niedergelassene Allergologen - diese Arbeit in ALLERGO JOURNAL gelesen. Wir haben selbst ähnliche Fälle erlebt, exemplarisch sei hier einer berichtet.

Bei einem Patienten mit eindeutiger Indikation zur spezifischen Нyposensibilisierung - generalisierte Reaktion und Nachweis der IgE-Vermittlung - leiten wir die Therapie ein. Nach Verabreichung der ersten drei Injektionen im Herbst wird die Behandlung beim Hausarzt - kein Allergologe! - fortgesetzt. Im Herbst des folgenden Jahres erscheint der Patient wieder bei uns mit der Bitte, ihm erneut die Hyposensibilisierungslösungen $\mathrm{zu}$ verschreiben. Auf unsere Nachfragen stellt sich heraus: Die vorhergehenden Injektionen wurden problemlos toleriert, auch bis zur Höchstdosis von $100 \mu \mathrm{g}$. Zu Beginn des Sommers wurde die Behandlung dann vom Hausarzt abgebrochen, da man „im Sommer, wenn die Pollen fliegen, nicht spritzt!" Und jetzt solle sie wieder eingeleitet werden ...

Wir denken, dass solche - wenn auch ,anekdotische“ - Ereignisse doch mitteilenswert sind. Sie stützen ganz

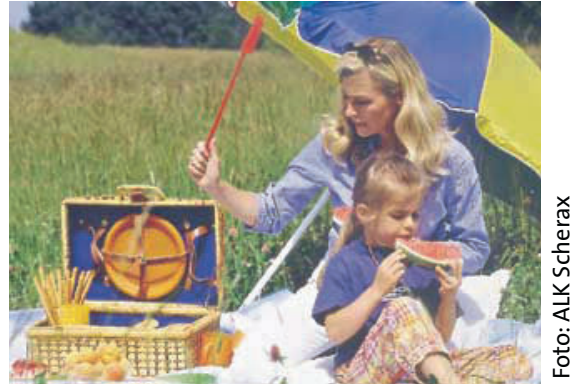

Eine erfolgreich abgeschlossene Hyposensibilisierung macht das Picknick entspannter.

und gar die Forderung, dass die Planung und fachliche Betreuung der spezifischen Hyposensibilisierung - natürlich nicht unbedingt die Gabe der einzelnen Injektionen - unbedingt in der Hand des erfahrenen Allergologen bleiben muss.

Dr. Thomas Smolin Gartenstraße 55 97616 Bad Neustad

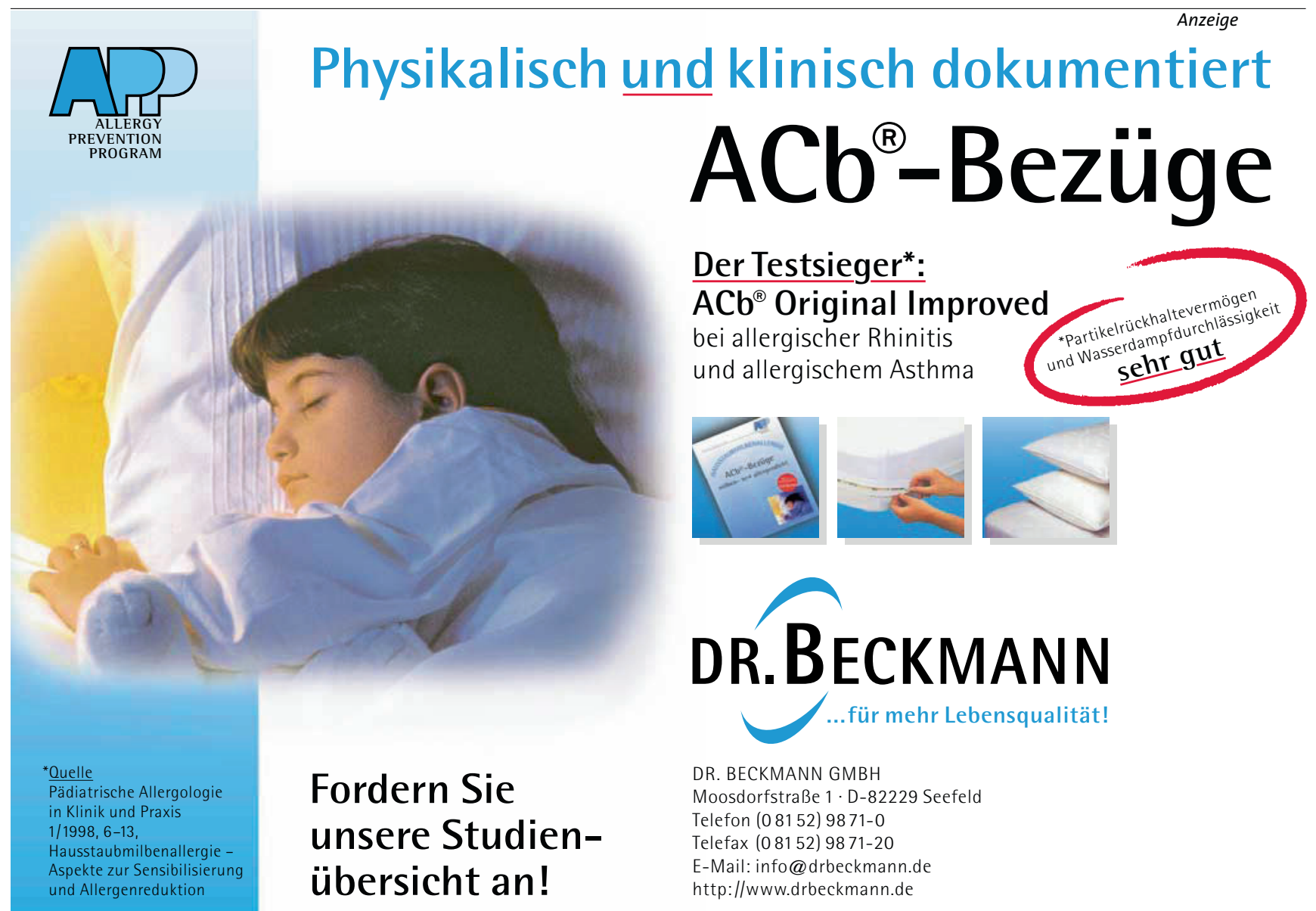

